\title{
Characterising Climate Change Discourse on Social Media During Extreme Weather Events
}

Keywords: twitter; climate change; extreme weather; social media; public perception.

\begin{abstract}
When extreme weather events occur, people often turn to social media platforms to share information, opinions and experiences. One of the topics commonly discussed is the role climate change may or may not have played in influencing an event. Here, we examine Twitter posts that mentioned climate change in the context of three high-magnitude extreme weather events - Hurricane Irene, Hurricane Sandy and Snowstorm Jonas - in order to assess how the framing of the topic and the attention paid to it can vary between events. We also examine the role that contextual factors can play in shaping climate change coverage on the platform. We find that criticism of climate change denial dominated during Irene, while political and ideological struggle frames dominated during Sandy. Discourse during Jonas was, in contrast, more divided between posts about the scientific links between climate change and the events, and posts contesting climate science in general. The focus on political and ideological struggle frames during Sandy reflects the event's occurrence at a time when the Occupy movement was active and the 2012 US Presidential Election was nearing. These factors, we suggest, also contributed to climate change being a more prominent discussion point during Sandy than during Irene or Jonas. The Jonas frames, meanwhile, hint at lesser public understanding of how climate change may influence cold weather events when compared with tropical storms. Overall, our findings demonstrate how event characteristics and short-term socio-political context can play a critical role in determining the lenses through which climate change is viewed.
\end{abstract}




\section{Introduction}

In recent years, the East Coast of the United States has played host to a succession of highmagnitude extreme weather events including Hurricane Irene in 2011, Hurricane Sandy in 2012 and Snowstorm Jonas in 2016. While these events cannot be singularly attributed to climate change $(1,2)$, the apparent upswing in the frequency of large storms in the region is consistent with scientific expectations in a warming world $(1,3-7)$. Consequently, the storms have stimulated renewed debate on climate change amongst the American public and within the country's media and political spheres.

Changes in the frequency and intensity of extreme weather will likely be the most prominent, near-term way in which many people experience the effects of climate change (7-9). Several studies have suggested that personal experience of extreme weather events that are associated with climate change has the potential to boost climate change belief, risk perception, and willingness to act (10-14). Therefore, when they occur, such events represent politically important moments for those wishing to influence popular perceptions around climate change. They offer the opportunity to discuss one of the most significant effects of climate change - increasingly severe extreme weather - while public attention is high and while the science has an elevated newsworthiness. However, the extent and manner of influence on public perception will in large part depend on whether the links between extreme events and climate change enter the public consciousness, and on how the links are framed.
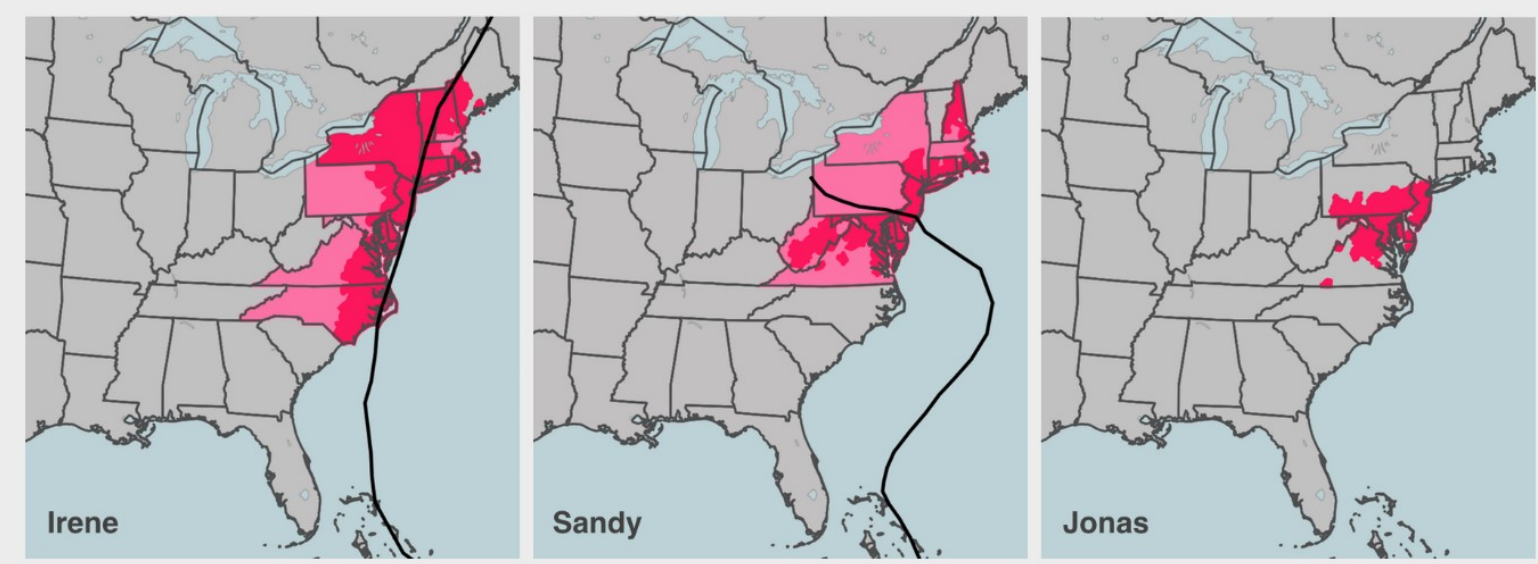

Legend:

Areas for which Major Disaster Declarations were issued

Areas for which Emergency Declarations were issued

— Tropical cyclone best track estimates

Figure 1. Areas for which Major Disaster Declarations or Emergency Declarations were issued in relation to each event and the best track estimates for Irene and Sandy (15-17). As Jonas was an extratropical cyclone, its track was less clearly defined so a discrete best path estimate is not available.

Television, newspaper, and radio outlets have traditionally been important meditators of the climate change discourse (18), determining whether the potential connections between climate change and the events will be discussed, and how. This has historically made the so-called legacy media hugely influential when it comes to shaping public understanding of climate change and the new era of extreme weather that it may be ushering in. The supremacy of the legacy media as an arbitrator of news is, however, now being challenged by the rise of online social media with potentially important repercussions for coverage of climate change. Over the past decade, social media platforms have emerged as an alternative medium through 
which people can access news and commentaries, and engage in debate. A 2016 Pew Research Center survey found that $62 \%$ of American adults now get news on social media sites, with $18 \%$ doing so regularly (19). The growth of social media as a source of news means platforms like Facebook and Twitter are joining legacy media as important mediators of discourse on climate change. This may be especially true during extreme weather events when use of social media and interest in climate change tend to simultaneously spike (20). However, the implications of this are yet to be fully understood and the nature of social media discourse around climate change during times of extreme weather is yet to be thoroughly characterised.

This paper makes a contribution to filling this gap in understanding by analysing Twitter posts that mentioned climate change in relation to Hurricane Irene, Hurricane Sandy and Snowstorm Jonas (see Fig. 1 for an overview of the areas affected; see SI Appendix A for descriptions of how each event may have been influenced by climate change). The study considers the prominence of climate change as a topic during each event; the spatial and temporal distribution of posts; and the ways in which the issue was framed. The potential implications of the findings for our understanding of public perceptions around the relationship between climate change and extreme weather are then discussed. Further details on each event are provided in the SI Appendix A.

\section{Background}

\section{Extreme weather and climate change perception}

Despite the international scientific community repeatedly affirming the existence of climate change and warning of the significant impacts it may entail (21), only $48 \%$ of American adults believe climate change is mostly due to human activity, and a mere $36 \%$ say they care a great deal about the issue (22). This discrepancy between scientific understanding and public sentiment has motivated a range of studies looking into the factors that shape perceptions of climate change - factors that may help to explain such polling (23). Several papers have cited the sense that climate change is a distant and intangible phenomenon as perhaps being particularly important in curtailing concern $(10,24,25)$. Intangibility and psychological distancing, it is argued, may assuage concern around climate change risks, while the former might also create scope for (erroneous) doubt about the very existence of global warming (10, 23).

Several studies have hypothesised that personal experience of climate change associated weather conditions - particularly weather extremes - might make climate change feel more visceral and less psychologically distant $(10,24,26)$. It follows that after exposure to such events, climate change belief is likely to be strengthened and concern is likely to rise $(25,26)$. This, of course, assumes that people first make the link between the conditions they experience and climate change, and as Weber (25) notes, there is also the possibility that exposure without adverse consequences may lower perceptions of risk. A further caveat is that experiential learning processes tend to show a strong recency bias $(25,26)$. As Taylor et al. (26) explain, "experiencing a highly negative event increases its availability from memory, which in turn increases the perceived likelihood of its re-occurrence". This can lead to overestimation of climate change risks following recent experiences and, conversely, underestimation once memories have faded (24-26). When there is a rapid succession of 
extremes - as when Sandy struck the United States Northeast just a year after Irene struck the same region - the tendency to overestimate may be particularly high.

The implication of the learning-from-experience theory is that by accentuating the links between climate change and events, such as Irene, Sandy and Jonas, it may be possible to better engage the affected populations with climate change issues and build support for mitigation and adaptation measures - at least while the events remain fresh in people's minds (10). Indeed, a study by Rudman et al. (11) found that New Jersey residents were more likely to vote for pro-environmental politicians following Hurricane Irene and Hurricane Sandy, compared with before. This is important because the literature suggests there are few other ways of readily generating the popular support necessary to facilitate large scale collective action on the issue (25). However, there are also warnings in the literature as to how generating strong emotional responses can become counterproductive by overwhelming people, leading to defeatism, avoidant behaviour, denial and apathy (26).

Evidence suggesting that personal experience of anomalous weather conditions can affect climate change perception is growing. Multiple studies in the United States have found a positive association (12-14, 27-29), as have several studies elsewhere in the world (10, 30, 31). However, extreme winter weather, such as Snowstorm Jonas, can be something of a complicating factor. A study by Shao and Goidel (32), looking at the effect of local weather conditions on climate belief in the Gulf Coast Region of the United States found that the downward trend in winter temperatures in recent years had negatively affected climate change belief. However, Capstick and Pidgeon, (30) in contrast, discovered that following a period of severe cold weather in the UK, three times as many people believed the event to be indicative of climate change than felt it to be disconfirming it.

Besides psychological distancing and intangibility, it should be recognised that there are multiple other factors which can affect perception and therefore potentially offset, bolster or act in lieu of the influence of personal experience in shaping perceptions; for example, confirmation bias is believed to be prevalent (32). This refers to the tendency to interpreting new information in a way that aligns with pre-existing beliefs. Motivated reasoning is also known to be important $(23,25)$. Shao and Goidel $(32)$, for instance, found that partisan affiliation had the strongest influence on perceptions of local weather along the United States Gulf Coast of any factor. They show that Democratic voters were not only more likely to be concerned about climate change than Republican voters in the region, but also more likely to perceive changes in the local climate, including changes in the frequency and intensity of hurricanes, droughts and floods (32).

Given climate change may have contributed to the intensity of Irene, Sandy and Jonas, and given many of those who tweeted about the events were likely to have been residing in affected areas, the datasets explored in this paper are very probably reflective of the influence of personal experience. Similarly, other factors shaping interpretation of the events, such as the previously mentioned confirmation bias and motivated reasoning, are likely to be evident. 
While the legacy media have traditionally been the focus of much of the scholarship around climate change communication, there is growing interest in the insights that data from Twitter can provide $(33,34)$. One of the most relevant studies in the context of this paper is a United States focussed investigation by Kirilenko et al. (20) that sought to establish whether personal experience of anomalous weather conditions affected engagement in climate change discourse on Twitter. They found that substantial local temperature anomalies did tend to result in a discernible increase in Twitter posts referring to climate change. The authors also identified significant spikes in tweeting activity during the timeframe of their data that corresponded to a number of high profile national and international climate change and weather-related events. The study did not, however, explore the nature of the climate change discourse, nor did it seek to examine specific events in depth. Sisco et al. (35) similarly used Twitter posts to examine the effect of various weather events that occurred in the United States on attention to climate change, assessing, in particular, the effect of different types of weather event. They found that a relatively wide range of weather events had detectable effects including coastal flooding, strong winds, excessive heat, droughts, extreme cold and heavy snow (35).

An earlier paper by Kirilenko and Stepchenkova (36) conducted a more globally oriented investigation of climate change posts on Twitter. In addition to also finding that certain news events catalysed discussion around climate change, they discovered that the flow of information on Twitter tended to be highly centralised, with "few media outlets, celebrities, and prominent bloggers leading the debate" (36). Pearce et al. (37), meanwhile, studied Twitter dynamics in relation to the release of the IPCC Working Group 1 report, finding that users were more likely to make "conversational connections with those who broadly share their views on climate change" (37). This provides some weight to the idea that social media can sometimes act like an echo chamber, repeating and reinforcing peoples pre-existing beliefs due to the self-curated nature of users' feeds. Williams et al. (38) similarly identified a tendency for users to interact with like-minded others, with polarised "sceptic" and "activist" communities forming as a result. However, as with Pearce et al. (37), they also found mixed-

Taking a different approach, Jang and Hart (39) examined how Twitter posts on climate change were framed, finding that within the United States, there was a particular tendency to "approach climate change issues in terms of whether global climate change is real or a lie" (39) - the "hoax" framing being much more frequently invoked than the "real" framing, especially in conservative leaning states. The study also found discussion around cause, impact, and solutions to be relatively niche. Jacques and Knox (40) also examined the frames through which climate change is viewed on Twitter, focusing very specifically on tweets posted during Hurricane Sandy that rejected the "orthodox climate consensus" - a topic highly pertinent to the study set out in this paper. The authors found that this rejection discourse largely drew on political rationale, rather than scientific rationale, and they further noted that the discourse tended to express certainty that climate science was a "wholesale fraud" (40). 
207 Of additional note in the context of this study is research that has looked at the use of Twitter during other types of emergency event. An early study by Palen et al. (41), for example, examined the spatio-temporal distribution of Twitter posts during the 2009 Red River Valley floods which affected an area spanning the US-Canadian border. They found that the types of information shared about the event changed with distance from the affected area and showed that attention to the event is sustained over time primarily by those who are local to the event (41). In another crisis focused study, Bruns and Burgess (42) examined tweeting activity following the 2011 earthquake that struck Christchurch, New Zealand. They documented the role Twitter played in the disseminating information and noted how the rate of posting slowed over time.

While the collective Twitter literature does provide a number of interesting insights into several facets of climate change discourse on Twitter, important gaps remain. In particular, there is a lack of knowledge about the particular nature of climate change discourse during extreme weather events. Few evaluations have so far been done of specific extreme weather events and where studies have been done, the focus has often been either on using the volume of Twitter posts as a proxy for attention paid to the subject or on exploring the dynamics of information flow. The content of climate change related tweets posted during extreme weather events has yet to be systematically explored.

\section{Changes to the Twitter ecosystem and society over time}

Less than two weeks after Irene dissipated (16), Twitter announced that its active user base had reached 100 million (43). Shortly after Sandy occurred, it announced that this figure had grown to 200 million (44) and by the time Jonas struck, the figure had risen yet further to 310 million (45). However, much of this growth came from outside of the United States (46). A Pew Research Center survey found that in August 2011, 12\% of American adults who were online used Twitter, by December 2012 this figure had risen to 16\% and by early 2016 it had reached $24 \%$ (47) - growth that, while substantial, is some way below the platforms headline growth.

In addition to changes in the size of the user base, analysis by Liu et al. (46) shows that the Twitter ecosystem also evolved in several other ways in the time between the events. In particular, there was a substantial rise in the median follower count; there was an increase in the rate of retweeting and a decline in replies; new tweeting conventions emerged; crossposting practices grew; spam and malicious behaviour became more prevalent; the platform was increasingly adopted by celebrities, companies and organisations; and there was a shift from desktop to mobile usage (46). Paralleling these changes, it is likely that there were also shifts in societal attitudes towards climate change and extreme weather (48) - shifts that the events themselves did not necessarily contribute to. Each of these changes affects the comparability of the datasets, though the precise nature of the affect cannot be readily determined. It is important, therefore, that the temporal context of the events is recognised 
Identification of climate change related posts. Once the event datasets were gathered, some Table 1. Search period and tweets returned in the case of each event.

\begin{tabular}{|c|c|c|}
\hline Event & Search period & Tweets returned \\
\hline Irene & 26 Aug $2011-12$ Sep 2011 & 3.29 million \\
\hline Sandy & 24 Oct $2012-5$ Nov 2012 & 11.60 million \\
\hline Jonas & 22 Jan $2016-30$ Jan 2016 & 1.71 million \\
\hline
\end{tabular}

Data source. For each of the extreme weather events under consideration we collected datasets of related tweets along with their associated metadata. The Irene and Jonas datasets were gathered using the Twitter Streaming API in near real-time, while the Sandy tweets were acquired post hoc using Gnip's Historical PowerTrack API. The latter tool provides paid-for access to the entire historical archive of public Twitter data and was necessary because the huge volume of Sandy related tweets that were posted as the storm made landfall exceeded our capacity to collect the complete population of posts using the Twitter Streaming API.

The World Meteorological Organization's practice of giving tropical cyclones short, distinctive names aids the identification of specific tropical cyclone events by keyword searches on Twitter as these names quickly become the predominant means by which individuals and organisations refer to the events. For Hurricane Irene, we therefore used the terms irene and hurricane as our keywords, while for Hurricane Sandy we simply used the term sandy. Traditionally, the tropical cyclone nomenclature has not been applied to other types of extreme weather system which makes identification of tweets citing non-tropical cyclone weather events more challenging. However, in recent years the Weather Channel (49) has begun unofficially naming major winter storms in the United States and a small number of winter storm related hashtags have gained prominence in the affected region. Together these developments aided our choice of keywords in the case of the January 2016 Winter Storm. We used The Weather Channel's name for the event, jonas, along with the following hashtags: winterstormjonas, blizzard2016, stormjonas, snowzilla, jonasblizzard, snowmageddon, and snowpocalypse.

For each dataset, visual inspection of samples indicates that the keywords predominantly returned true positives for the storms. A relatively small number of false positives were seen where our keywords represented a substring of a different word, where keywords were part of existing Twitter user names, and where the keywords were used in entirely different contexts. However, the infrequency of these cases and the subsequent methods used in the analysis means their impact on the overall results should be negligible. In each case, the datasets cover periods before, during, and after the storms passed over the East Coast of the United States. Table 1 provides details of the search periods and the number of posts returned. basic cleaning was performed. This included removal of non-alphanumeric characters and URLs, conversion of all text to lowercase, and correction of common spelling mistakes. The 
climate change related tweets contained within the datasets were then identified, using keyword matches as before. It was found that simply using the search terms climate change and global warming (with and without the space) resulted in a substantial number of false negatives. However, it was also found that broadening the search to also include any post containing the terms climate led to a substantial number of false positives. Consequently, a more sophisticated set of search rules was designed in which the terms climate or global had to occur along with one of a number of secondary terms for a match to be made - in some cases, these words needed to occur in order, while in other cases order did not matter (see Table 2). This approach appears to substantially reduce the overall number of false results. Pure substring matches were used to account for words being potentially concatenated in hashtags and to allow for a variety of potential suffixes. Throughout the paper, we refer to tweets identified using these rules as climate change tweets.

Table 2. Search rules used to identify climate change related posts. The vertical bar is used to symbolise the or operator.

\begin{tabular}{|l|l|}
\hline \multicolumn{2}{|l|}{ The following terms can occur in any order: } \\
\hline Term 1 & Term 2 \\
\hline climate & $\begin{array}{l}\text { chang } \mid \text { denial } \mid \text { denier } \mid \text { deny } \mid \text { carbon } \mid \text { connect } \mid \text { link | new normal | pearl } \\
\text { harbour } \mid \text { science } \mid \text { scientist } \mid \text { sea level } \mid \text { sceptic | skeptic | wakeup call | wakeupcall | warming }\end{array}$ \\
global & cooling $\mid$ warming \\
\hline $\begin{array}{l}\text { The following terms must occur in the order specified, either with or without a space: } \\
\text { Term } 1\end{array}$ & Term 2 \\
\hline climate & silence $\mid$ crisis | action \\
\hline
\end{tabular}

Basic data attributes. Once the climate change related tweets were extracted from the main event datasets, the basic attributes of the climate change posts were explored. Firstly, the relative composition of retweets to non-retweets was calculated both at an aggregate level and temporally. The retweets were identified through the presence of the character string "RT" at the start of posts. Secondly, the number of times each retweeted post was shared was analysed. This was done through calculating the frequency of occurrence of each unique string in the subset of posts previously identified as retweets. This means that only retweets made during the timeframe of the dataset are considered. It should be noted that modified retweets and retweets of retweets will be counted as distinct from unmodified retweets of the original as they will not return string matches. Thirdly, the number of unique users who posted tweets was calculated using the user IDs provided in the metadata.

Spatial distribution of posts. The geographical origin of posts was also assessed by analysing the geolocation metadata that is included in the datasets. As providing geolocation data with posts is optional for users of the Twitter platform, this geolocation data is not available for all posts. In fact, less than $2 \%$ of the event posts are geotagged. Consequently, geolocation data is distinctly sparse for the Irene and Jonas climate change posts. Geographical analysis was therefore performed on the event datasets as a whole rather than being restricted to the subset of climate change posts. We assume that the spatial distribution of climate change posts will hold similarities with the spatial distribution of event posts, though a degree of deviation is likely. In order to assess the cumulative percentage of geotagged posts by distance from areas where Major Disaster Declarations were issued, shapefiles showing areas where Major 
Disasters had been declared for each event were downloaded from the FEMA website (15) 330 and merged. The distance of the geotagged posts from the merged shapefiles was then calculated. This was done with the aid of the 'gBuffer' function from the R package 'rgeos' (50) and the 'over' function from the R package 'sp' (51).

Climate change discourse. The discourse in the climate change posts was explored using a method developed by $\mathrm{O}^{\prime}$ Neill et al. (52) for assessing how climate change is framed in media reports. Climate change related posts that were retweeted sufficiently frequently as to collectively exceed $0.1 \%$ of total climate change related tweets were assessed against a frame coding schema and assigned to the frame category that best matched the content of the post. Twenty-four retweets met the threshold conditions for assessment in the case of Irene, sixtyfour in the case of Sandy, and ninety-six in the case of Jonas. The frame coding schema included eleven frames (see Table 3). These were derived, for the most part, from the schema set out in $\mathrm{O}^{\prime}$ Neill et al. (52), although supplemental frames were added and the definitions of others were adjusted to better reflect the nature of the frames we identified in the datasets when piloting the schema (details of the alterations made are provided in SI Appendix B). The coding process followed the guidance provided in $\mathrm{O}^{\prime}$ Neill et al. (52). Frames were independently assigned to posts by two coders who considered the presence (or absence) of narrative themes, quoted sources, user mentions, keywords, hashtags, metaphors and URLs. Where coders judged posts to be ambiguous after considering the presence or absence of these features, past tweets and the Twitter "bio" of the post's author was also taken into consideration. In cases where ambiguity still remained after this, posts were assigned "NA" in the coding datasheet. After frames had been assigned to all of the posts, the two coders datasheets were compared with the initial inter-coder reliability assessed using Cohen's kappa. This yielded a score of 0.891 which indicates substantial agreement. Where different codes were found to have been assigned to a post, coders discussed the reasoning behind their choice and agreed on a single principal code.

Table 3. The climate change frames considered in the study (adapted from O'Neill, 2015, p.381).

\begin{tabular}{|c|c|}
\hline Frame & Brief description \\
\hline Settled Science (SS) & $\begin{array}{l}\text { Focus on the broad expert consensus around the science of climate change. SS1: } \\
\text { Affirming that the fundamental science of climate change is settled. SS2: Criticism of } \\
\text { those promoting contrarian views. }\end{array}$ \\
\hline Extremes (EX) & $\begin{array}{l}\text { Emphasis on the links between climate change and extreme weather events. Climate } \\
\text { change may lead to an increase in the frequency and intensity of extreme weather } \\
\text { events. Climate change may exacerbate the impacts of extreme weather events. }\end{array}$ \\
\hline Uncertain Science (US) & $\begin{array}{l}\text { The existence of climate change is not explicitly questioned, but uncertainty in the } \\
\text { science, impacts, and solutions may be raised. Attribution claims are treated with } \\
\text { scepticism. }\end{array}$ \\
\hline Contested Science (CS) & $\begin{array}{l}\text { Climate science is explicitly contested. The idea that climate change is occurring or is } \\
\text { primarily driven by anthropogenic actions is challenged. The idea that climate change } \\
\text { may be having an influence on the frequency or nature of extreme weather events is } \\
\text { challenged. }\end{array}$ \\
\hline $\begin{array}{l}\text { Political or Ideological } \\
\text { Struggle (PIS) }\end{array}$ & $\begin{array}{l}\text { Links are made between climate change, the ongoing extreme weather events, and the } \\
\text { happenings in the political and media spheres. }\end{array}$ \\
\hline Economic $(\mathrm{E})$ & $\begin{array}{l}\text { Emphasis on the economic implications of climate change or climate change action. E1: } \\
\text { The economic case for acting is made. Reference may be made to the cost of climate } \\
\text { change exacerbated extreme weather. E2: Climate change mitigation and adaptation } \\
\text { will be hugely expensive. Other issues should take priority. }\end{array}$ \\
\hline Role of Science (ROS) & $\begin{array}{l}\text { Focuses on the role science and scientists should play in society, rather than on the } \\
\text { science itself. May also discuss transparency, science funding, and the role of scientists } \\
\text { in raising awareness. }\end{array}$ \\
\hline Opportunity (O) & $\begin{array}{l}\text { Climate change as an opportunity. O1: Acting on climate change offers potential co- } \\
\text { benefits for society and the environment. O2: The impacts of climate change may } \\
\text { themselves create new opportunities. }\end{array}$ \\
\hline
\end{tabular}




\begin{tabular}{|l|l|}
$\begin{array}{l}\text { Morality and Ethics } \\
\text { (ME) }\end{array}$ & $\begin{array}{l}\text { Moral, religious, or ethical arguments are invoked, either ME1: for action or ME2: for } \\
\text { no action. }\end{array}$ \\
\hline $\begin{array}{l}\text { Health }(\mathrm{H}) \\
\text { Security }(\mathrm{S})\end{array}$ & $\begin{array}{l}\text { Focuses on the potential implications of climate change for human health. } \\
\text { Emphasis is placed on the risks climate change poses to human security. Issues around } \\
\text { energy, water, and food security may be raised, as may mass migration. }\end{array}$ \\
\hline $\begin{array}{l}\text { The principal frame cannot be determine with reasonable confidence or does not align } \\
\text { with any of the above definitions. }\end{array}$ \\
\hline
\end{tabular}

358

359

360

\section{Results}

In all, the Irene dataset contains 3.29 million posts, the Sandy dataset contains 11.60 million posts and the Jonas dataset contains 1.71 million posts. Terms pertaining to climate change were identified in 6,286 of the Irene posts, 99,823 of the Sandy posts and 5,326 of the Jonas posts. The total number of users who posted about climate change was 6,000 in the case of Irene, 67,613 in the case of Sandy, and 4,520 in the case of Jonas. Of those who posted about climate change, $3.43 \%$ did so more than once in the case of Irene, $19.34 \%$ did so more than once in the case of Sandy, and $10.97 \%$ did so more than once in the case of Jonas.

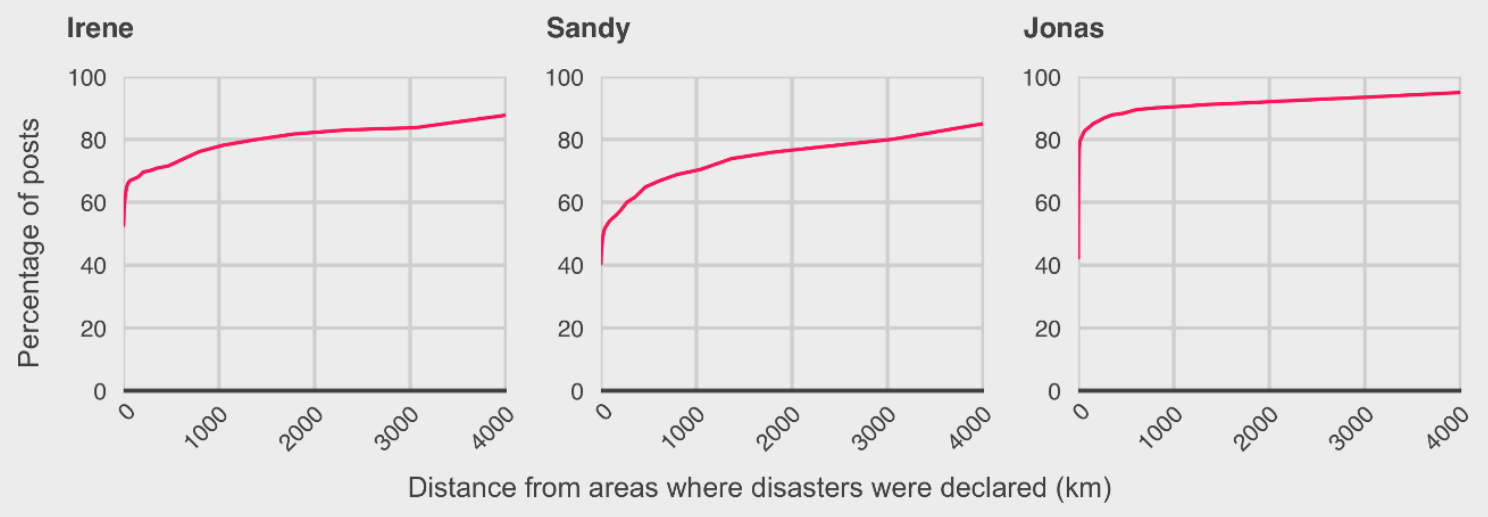

Figure 2. Cumulative percentage of geotagged posts by distance from areas where Major Disaster Declarations were issued.

Spatial distribution of posts. The geographical origin of a small proportion of the event posts $(\sim 1 \%)$ is included in the post metadata. A total of $59.62 \%$ of the geotagged Irene posts, $45.80 \%$ of the geotagged Sandy posts and $76.28 \%$ of the geotagged Jonas posts have coordinates that lie within 10 kilometres of areas where Major Disasters were declared during the respective events (Fig. 2). This suggests that a large proportion of the tweets are likely to have been posted by people who personally experienced the storms, with interest being particularly localised to the affected areas in the case of Jonas and relatively widespread in the case of Sandy.

Temporal dynamics of posts. The temporal dynamics of the climate change posts are shown in Fig. 3. The dashed line, $t$, represents the moment of the New Jersey landfall in the case of Irene and Sandy, and the approximate midpoint of the snowfall over the Atlantic states in the case of Jonas. The average hourly number of climate change posts prior to $t$ was 24.25 for Irene, 113.39 for Sandy and 76.86 for Jonas. Over the 72-hour period following $t$, the average climbed to 68.22 for Irene and 938.88 for Sandy but fell to 32.29 for Jonas - very substantial shifts in each instance. The proportion of event posts that the climate change tweets 
constituted also varied over time, with the relative significance of climate change as a discussion point increasing after $t$ in each instance. Prior to $t$, climate change posts constituted $0.07 \%$ of all Irene posts, $0.26 \%$ of all Sandy posts and $0.30 \%$ of all Jonas posts, while after $t$ the figures rose to $0.38 \%, 1.16 \%$ and $0.35 \%$ respectively. Notably, these averages mask numerous posts rather than by surges in the creation of original content.
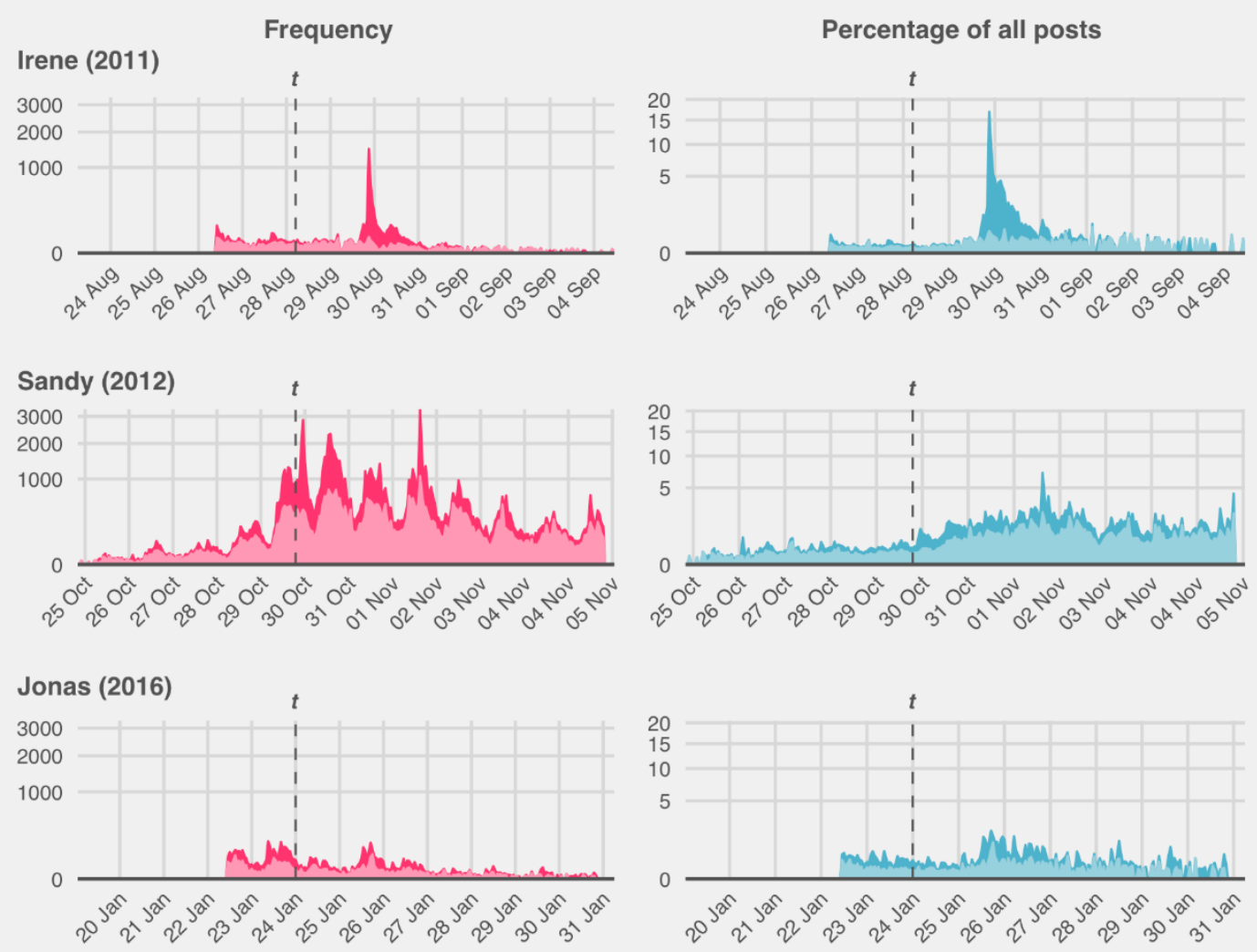

Legend:

Climate change posts that are retweets

Climate change posts that are original posts

Percentage of total posts that are retweeted climate change posts

Percentage of total posts that are original climate change posts

Figure 3. The leftmost charts show the absolute frequency of posts that mentioned climate change during each event on an hourly basis, while the rightmost charts show the proportion of all posts during each hour that mentioned climate change. The dashed line, $t$, represents the moment of the New Jersey landfall in the case of Irene and Sandy, and the approximate midpoint of the snowfall over the Atlantic states in the case of Jonas. Dates and times are in accordance with the Eastern Time Zone.

Retweets. On Twitter, re-posted tweets are known as retweets. The practice of retweeting is commonly employed by users to share with their own followers a tweet that another user has posted. Such posts constitute $76.2 \%$ of the Irene climate change tweets, $54.9 \%$ of the Sandy climate change tweets, and $66.8 \%$ of the Jonas climate change tweets. The proportion of posts that are retweets in the unfiltered Sandy and Jonas datasets is slightly lower at $48.9 \%$ and $64.9 \%$ respectively. However, in the case of Irene, the difference in retweeting rates between the unfiltered dataset and the climate change subset is very substantial as only $29.5 \%$ of the posts in the unfiltered Irene dataset are retweets. As Fig. 4 shows, the distribution of retweets across climate change posts is heavily skewed, with a long-tail - a small proportion of the posts attracted a large proportion of the retweets. The unequal distribution is particularly 
pronounced in the case of Irene with retweets of a single post ultimately constituting $57.8 \%$ of the entire climate change posts.
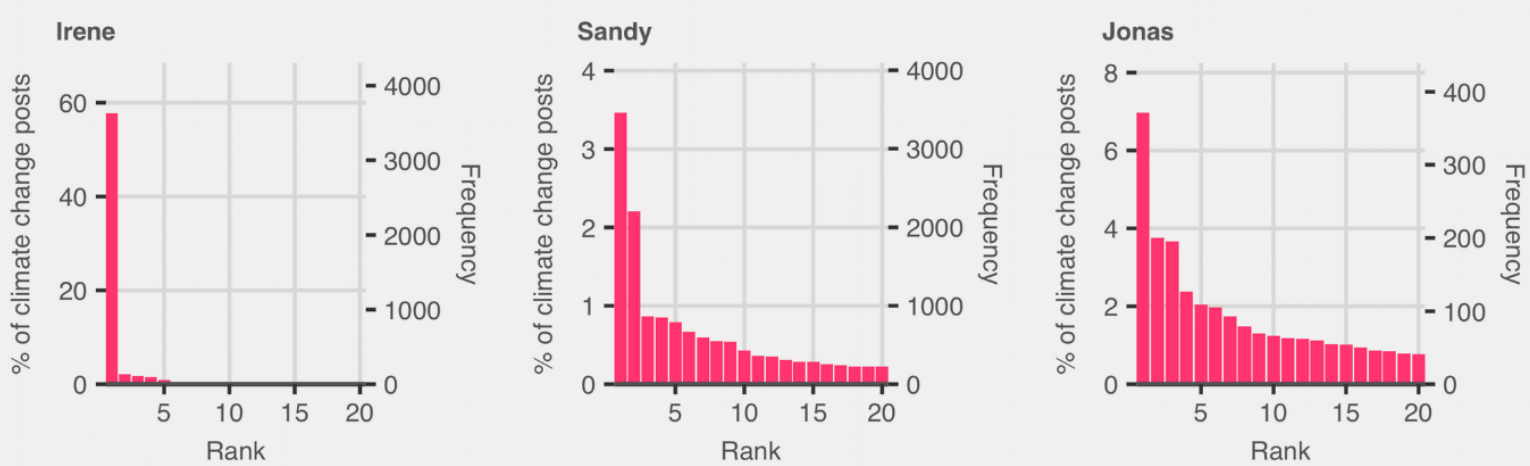

Figure 4. Number of times the top twenty climate change retweets from each event were shared, ordered by frequency.

Frames invoked in the most frequently retweeted posts. In order to identify the main frames through which climate change was viewed during the events, we assessed the most frequently retweeted climate change posts in each dataset against a frame coding schema (Table 3) and assigned each post to the frame that best matched the content of the post (see Materials and Methods for more detail). As the assessed posts constituted a substantial portion of the total climate change posts $-67.47 \%$ in the case of Irene, $20.46 \%$ in the case of Sandy and $57.04 \%$ in the case of Jonas - the findings provide a good sense of the frames through which many users will have viewed the topic.

As illustrated in Fig. 5, each dataset is characterised by notably different principal climate change frames. For Irene, the retweet discourse was dominated by a post that engaged in criticism of climate change denial and affirmed the existence of climate change (SS2). This post also had a secondary frame of a political dimension, as it specifically cited a Republican politician known for having described climate change as a "hoax". In the case of Sandy, meanwhile, the political or ideological struggle frame (PIS) was the most prevalent. Many of the posts that fall within this frame referred to the 2012 presidential campaign which was drawing towards a conclusion around the time that Sandy struck. Criticism of the media was also a common theme within the PIS frame. In particular, a perceived lack of airtime and column inches given to the topic of climate change when Hurricane Sandy and the Presidential Election were being discussed was frequently raised as an issue. Criticism of those promoting contrarian views (SS2) and posts emphasising the links between climate change and extreme weather events (EX) also had a notable presence. In the case of Jonas, two frames were dominant, rather than one. Marginally leading the way in total retweets was the extremes frame (EX), with many of the posts highlighting the ways in which climate change could exacerbate snowstorms such as Jonas. The second frame, however, was the contested science frame (CS). The posts that fell within this category tended to cite the snowstorm as evidence that climate change was not occurring.

Only one of the retweets we considered appealed directly to economic arguments (E). Posted during Irene, it raised concerns about damages that will be incurred from increasingly intense storms. Notably, none of the retweets that met our consideration threshold invoked health $(\mathrm{H})$, morality and ethics $(\mathrm{ME})$, opportunity $(\mathrm{O})$ or role of science $(\mathrm{ROS})$ as principal frames. 

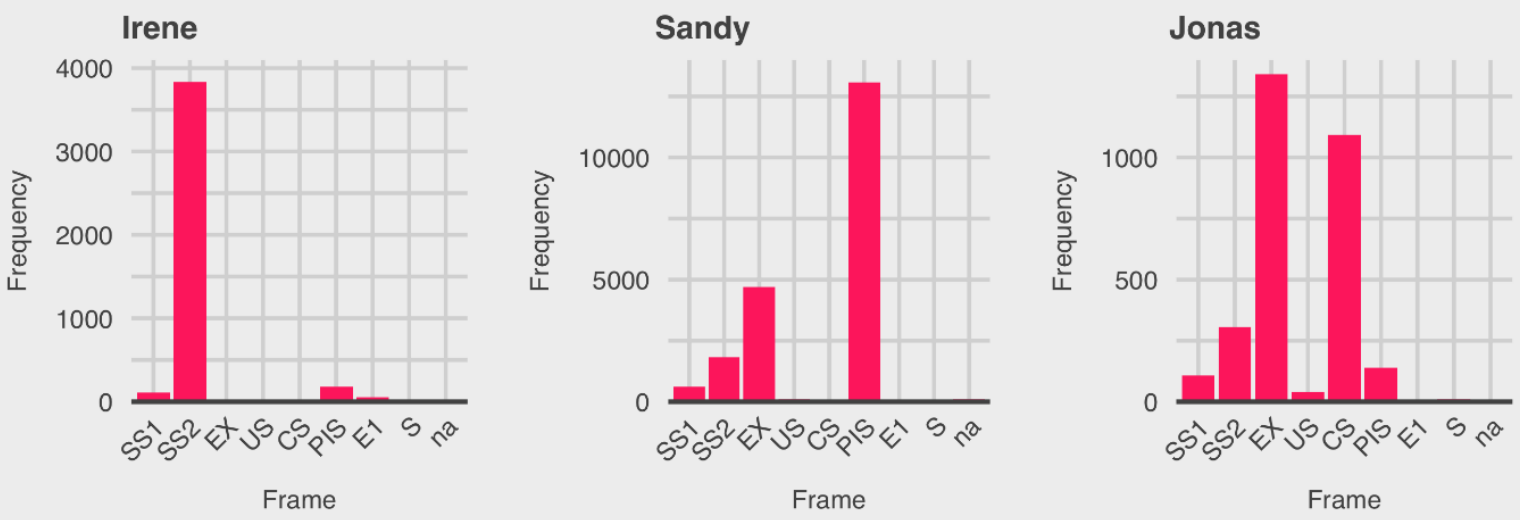

451

452

453

454

455

456

457

458

459

460

461

462

463

464

465

466

467

468

469

470

471

472

473

474

475

476

477

478

479

480

481

482

483

484

485

486

Figure 5. The total number of retweets by principal frame used in the original posts. Only the frames that were identified within the posts are included in the charts.

\section{Discussion}

The overall attention that each event drew on Twitter appears to reflect, at least in part, the socio-economic impact the storms had in the Northeastern region of the United States. Sandy caused the greatest damage, resulted in the most fatalities and attracted the most posts, while Jonas caused the least damage, resulted in the fewest fatalities and attracted the fewest posts $(53,54)$. Irene, meanwhile, lay somewhere in between on each count $(55)$. These differences in the overall impact of the events are likely to have contributed to the differing number of climate change tweets posted during each storm. However, discrepancies in the proportion of posts that mention climate change across the events suggest other factors were also important in determining the attention paid to the topic. Sandy, in particular, stands out with $0.86 \%$ of all event posts mentioning climate change - a figure far in excess of the $0.19 \%$ of Irene posts and $0.31 \%$ of Jonas posts that raised the subject. The depth of user engagement in talking about climate change is also somewhat greater in the case of Sandy, with more users posting multiple climate change tweets.

Sandy. The politically charged context in which Sandy occurred seems to have been an important factor in spurring much of the attention paid to climate change during the event. The Occupy movement, which began shortly after Irene had struck in 2011, was well established by the time Sandy rode up the East Coast and the United States presidential election of 2012 was drawing to a climax - election day was the 6 November, while the storm made landfall on the evening of 29 October. The most frequently retweeted post was written by @YourAnonNews, an account controlled by the hactivist group Anonymous - a group that was closely entwined with the Occupy movement at the time. The post implied links between the storm and climate change, while arguing that climate change was not being adequately discussed in the public and political spheres. The second most retweeted post was written by $\mathrm{Al}$ Gore, the former Vice President of the United States and prominent environmentalist. He called for people to work together to "solve the climate crisis," stating that "Sandy is a warning". Common topics in the other widely retweeted posts included the perceived lack of media coverage of the climate change issue, its lack of prominence in the election campaigns, and the endorsement of Barack Obama by the then Mayor of New York City because of the president's support for action on climate change. Although some of these posts represented little more than news reports, a substantial number of them seem to have been implicitly or 
explicitly using Sandy as a means to push climate change up the political agenda and to raise public consciousness of the issue.

Notably, the news outlets that have traditionally been influential in shaping the popular discourse in the United States were among the most frequently retweeted and referenced during Sandy. Among the 30 most retweeted climate change posts in the Sandy dataset were tweets from NBC News, ${ }^{1}$ CBS News, Time, the New York Times, and then CNN host, Piers Morgan (see SI Appendix C2). This demonstrates, as Bruns and Burgess (56) note, that Twitter is not separate from, but increasingly embedded into the larger media landscape, complementing rather than replacing traditional information sources. Interestingly, during Irene and Jonas, traditional mainstream news outlets were much less prominent. This was typically because they were not posting about climate change in relation to the events, rather than because they were not being retweeted. Seventeen tweets linking Sandy to climate change were identified as having been posted by major newspapers ${ }^{2}$ from the Northeastern United States. The number was just four in the case of Irene and zero in the case of Jonas. Lower profile groups and non-affiliated individuals were therefore more important in driving climate change discussion during Irene and Jonas.

As previously mentioned, discussion of climate change within the Sandy dataset increased dramatically in both relative and absolute terms following the storm's New Jersey landfall an increase which was largely sustained in the days immediately afterwards. This indicates that landfall was something of a catalyst for climate change discussion and it shows that climate change as a discussion point had greater longevity than many other discussion points. This relatively greater longevity, we hypothesise, was because climate change discussions were largely a product of reflection on the meaning and implications of the event. To a degree, this theory also holds for Irene and Jonas. In both absolute and relative terms, climate change posts increased after Irene's New Jersey landfall, although much of this was down to a single post. While climate change posts only increased in relative terms following Jonas, many of the Jonas posts that did not fall under the contested science (CS) frame were posted after the midpoint of the event.

Irene. In both absolute and relative terms, there were substantially fewer posts pertaining to climate change within the Irene dataset, compared to the Sandy dataset - this despite both storms being tropical cyclones and both making landfall in the Northeastern United States within 430 days of one another. Several factors may have contributed to this. Firstly, the storm occurred during a less politically charged period. Secondly, while Irene caused substantial damage and disruption in places, its overall impact was not as historically notable as Sandy's. We therefore speculate that it may not have been regarded as so historically anomalous and therefore suggestive of climate change. Thirdly, given major tropical cyclone landfalls are relatively unusual in the Northeastern United States, Sandy had the additional notability over Irene of having occurred so soon after another major storm. Fourthly, discussion of climate change during Sandy was boosted by numerous high-profile public figures speaking out on the issue. For example, posts by Al Gore, Ian Somerhalder, Ricky Gervais and Naomi Klein were all widely retweeted. Similarly, statements by the likes of the Mayor of New York City and articles by news organisations and campaign groups helped draw attention to the subject

\footnotetext{
1 Under the handle: @BreakingNews.

2 Major newspapers are defined here as newspapers with a circulation of 250,000+. The accounts included in the analysis were restricted to the principal news and science accounts used by the newspapers. These were: @wsj, @wsjscience, @nytimes, @nytscience, @usatoday, @nydailynews, @newyorkpost, @washingtonpost, @posthealthsci, @newsday, @starledger, @phillyinquirer, @bostonglobe and @globedatadesk.
} 
as evidenced by their presence in the lists of top retweets (see SI Appendix C2). Much of this was lacking during Irene. Growth in Twitter's user base in the time between Irene and Sandy is also likely to have swelled the number of posts in the latter case - the number of online adults using Twitter in the United States increased by 33\% between August 2011 and December 2012 (47). However, this user base growth cannot explain the greater relative importance of the climate change topic in the Sandy dataset.

Another notable difference between the Irene and Sandy climate change data is that the Irene multiple postings by users - features that point to lesser user engagement in the topic of climate change. Consequently, not only did Sandy generate broader interest in the subject, it also seems to have generated deeper interest. The post that dominates the retweets in the Irene climate change data shares an affinity with the political and ideological frame that characterises many of the Sandy posts, even though its primary focus is on criticising climate change denial. However, other frames noted in the Sandy and Jonas tweets are notable only by their relative or absolute absence from the top Irene retweets.

Jonas. Like Irene, Jonas attracted far fewer climate change tweets than Sandy did, both in absolute and relative terms. The gulf in the number of posts is especially large if growth in the user base is considered - the number of online adults in the United States using Twitter grew by $50 \%$ in the interval between Sandy and Jonas. However, in relative terms, climate change was a more prominent topic within the Jonas dataset when compared with the Irene dataset. This may be partially explained by larger numbers of climate change sceptics posting on the topic during Jonas than in the case of Irene. As individuals and groups concerned with climate change were also active, the posts by sceptics served to bolster the total number of climate change posts. While Jonas occurred in a presidential election year like Sandy did, it struck earlier in the campaign cycle. Reflecting this, the election campaigns did not feature prominently in the posts. The Occupy movement had also waned in the time since Sandy. Notably, the Jonas climate change posts also contained few references to the Paris climate accord which was adopted just a month prior to the storm. "Paris" was mentioned in just $0.19 \%$ of the climate change posts. Indeed, contextual references to contemporary sociopolitical events were less common in the Jonas climate change posts than in the other event datasets.

The two main framings seen in the Jonas retweets - the extremes frame (EX) and the contested science frame (CS) - are distinct from those seen in the Irene and Sandy retweets. The greater presence of the contested science frame in the Jonas posts is unsurprising given extreme cold weather events are not likely to fit with many people's image of what might be expected to happen in a warming world. Consistent with previous research (40), we find that the posts contesting climate science typically expressed certainty that anthropogenic climate change is a hoax and we find that such posts tended to focus on politics rather than science. Indeed, many of them utilised hashtags associated with right wing groups (e.g. \#RedNationRising and \#TCOT) and characterised those who believe in climate change as liberals while invoking contemptuous language (see SI Appendix C3). This indicates that the authors of these posts view climate change at least in part as a left-wing machination. In this respect, the political or ideological struggle frame (PIS) may be considered an important secondary frame. Notably, these posts tend not to explain why they cite Jonas as evidence against climate change. These reasons must be inferred by the reader which indicates that the authors assume their logic will be intuitively obvious to their audience. By contrast, the extremes (EX) frame posts were very much focused on articulating the scientific links between Jonas and climate change. We suggest that by sharing these posts users hoped to inform others of the possible links between 
climate change and the storm, recognising that potential links between climate change and cold weather events are not necessarily intuitive or well-known. Users may also have wanted to close down speculation that Jonas disproved climate change. That the extremes (EX) frame was, in relative terms, used less frequently in the case of Irene and Sandy suggests the links between climate change and tropical cyclones are thought to be better known and therefore in less need of articulating.

Given Jang and Hart (39) found that hoax frames typically prevail in the Twitter discourse within the United States, the parity of hoax and non-hoax frames during Jonas and the dominance of non-hoax frames during Irene and Sandy, represents a departure from the norm. It suggests that extreme weather events not only increase the profile of climate change as a topic on Twitter, they tangibly alter the balance of frames used to discuss the issue, at least for a short while. The relative absence of the political or ideological struggle (PIS) frame and relative lack of criticism of those promoting contrarian views (SS2) is notable in the Jonas data. One of the consequences of this is that the adversarial language invoked during Irene and Sandy by supporters of action on climate change has largely been replaced by factual argument. This, we suggest, may reflect a belief that factual argument is needed to contest climate change denial when seemingly counterintuitive evidence is encountered and used to contest the science.

\section{Conclusions}

In this study, we examined the nature of climate change discussions on Twitter during Hurricane Irene, Hurricane Sandy and Snowstorm Jonas. We found that the degree of attention the topic received varied, both in absolute and relative terms, between the events. Furthermore, the way the topic tended to be framed also differed in each case.

When the growth of the Twitter user base is accounted for, it is clear that Sandy garnered by far the greatest attention, followed at a distance by Irene and then Jonas. This sequence reflects the relative socio-economic impact each storm had in the Northeastern region of the United States. However, the magnitude of the difference between Irene and Sandy in terms of climate change posts is more than would be expected based on impact alone. Instead, it seems that the socio-political context in which the Sandy occurred helped draw particularly substantial attention to the topic. That said, factors such as the storms exceptional size (57) and its ranking as the second-costliest cyclone to hit the United States since 1990 (17) will likely also have contributed to the tweet tally. The role the mainstream media played in focusing attention on the subject during Sandy appears to have been important as well. Several news outlets posted tweets that were widely shared, and content that news outlets posted elsewhere on the internet was also frequently cited - something which points to the continued importance of the legacy media. During Irene and Jonas, few mainstream news outlets posted on the subject. While this may help explain the smaller number of climate change posts the events generated in both relative and absolute terms, it is notable that thousands of tweets were still posted on the topic in each case. This shows how non-traditional actors are still able to give the issue voice through posting on the platform.

In respect to frames, we found that the meteorological characteristics of the storms and the socio-political context in which they occurred both played an important role in shaping the lenses through which climate change was viewed during each event. Particularly notable was the relative absence of the contested science (CS) and uncertain science (US) frames within the top Irene and Sandy retweets given that hoax frames have been found to normally prevail in 
the Twitter discourse within the United States (39). Even during Jonas, the contested science (CS) frame trailed behind the extremes (EX) frame. This suggests that extreme weather events cause a substantial shift in the balance of climate change coverage on Twitter towards nonhoax perspectives.

An important caveat to our findings is that the events we have considered occurred at different points over a four-and-a-half-year period. As we discuss in greater depth earlier, both the Twitter ecosystem and societal attitudes towards climate change evolved over this period with implications for the comparability of the events. Consequently, it is important to recognise the events as situated in time. With this in mind, we recommend that future studies consider how the frames used in climate change posts have changed over the years. We also suggest research be done to assess whether extreme weather events have a discernible lasting impact on the frames used to discuss the topic.

As Weber and Stern note (58), accurate or not, media reports have the capacity to influence people's thoughts and feelings. Although they were referring to traditional media reports, what they say is also applicable to social media posts - a 2016 Pew Research Center survey found that $20 \%$ of social media users in the United States had changed their views on a political or social issue because of something they saw on social media (47). This makes the rise in the number of posts expressing concern about climate change during extreme weather events important. The more posts there are that express concern, the more people are likely to see them, and so the greater the potential for building support for action on the issue. Even if the posts do not influence the views of other users, the elevated profile they give to the issue can still be politically important and can feedback into future coverage of extreme weather events through raising awareness of potential links between weather extremes and climate change.

661

662

663

664

665

666

\section{References}

1. Knutson TR, et al. (2010) Tropical cyclones and climate change. Nat Geosci 3(3):157163.

2. Elsner JB, Kossin JP, Jagger TH (2008) The increasing intensity of the strongest

tropical cyclones. Nature 455(7209):92-95.

3. Emanuel K (2005) Increasing destructiveness of tropical cyclones over the past 30

years. Nature 436(7051):686-688.

4. Villarini G, Vecchi G (2013) Projected Increases in North Atlantic Tropical Cyclone Intensity from CMIP5 Models. J Clim 26(10):3231-3240.

5. Changnon SA, Changnon D, Karl TR (2006) Temporal and Spatial Characteristics of Snowstorms in the Contiguous United States. Am Meteorol Soc 45(August 2006):11411155.

6. Kunkel KE, et al. (2013) Extreme Storms: State of Knowledge. Am Meteorol Soc 94(4):499-514.

7. NASEM (2016) Attribution of Extreme Weather Events in the Context of Climate Change

(The National Academies Press, Washington DC) doi:10.17226/21852.

8. Coumou D, Rahmstorf S (2012) A decade of weather extremes. Nat Clim Chang

2(7):491-496.

9. Trenberth KE (2012) Framing the way to relate climate extremes to climate change. Clim Change 115(2):283-290.

10. Spence A, Poortinga W, Butler C, Pidgeon NF (2011) Perceptions of climate change and willingness to save energy related to flood experience. Nat Clim Chang 1(1):46-49. 
11. Rudman LA, McLean MC, Bunzl M (2013) When truth is personally inconvenient, attitudes change the impact of extreme weather on implicit support for green politicians and explicit climate-change beliefs. Psychol Sci 24(11):1-7.

12. Myers TA, Maibach EW, Roser-Renouf C, Akerlof K, Leiserowitz AA (2012) The relationship between personal experience and belief in the reality of global warming. Nat Clim Chang 3(4):343-347.

13. Deryugina T (2013) How do people update? The effects of local weather fluctuations on beliefs about global warming. Clim Change 118(2):397-416.

14. Egan PJ, Mullin M (2012) Turning personal experience into political attitudes: the effect of local weather on Americans' perceptions about global warming. J Polit 74(3):796-809.

15. FEMA (2016) Disaster Declarations. Available at: https://www.fema.gov/disasters?field_state_tid_selective=All\&field_disaster_type_t erm_tid=All\&field_disaster_declaration_type_value=All\&items_per_page $=20$ [Accessed May 15, 2016].

16. Avila LA, Cangialosi J (2011) Tropical Cyclone Report: Hurricane Irene (AL092011) Available at: http://www.nhc.noaa.gov/data/tcr/AL092011_Irene.pdf.

17. Blake ES, Kimberlain TB, Berg RJ, Cangialosi JP, Beven II JL (2012) Tropical Cyclone Report: Hurricane Sandy (AL182012) Available at:

http://www.nhc.noaa.gov/data/tcr/AL182012_Sandy.pdf.

18. Leiserowitz A, Smith N, Marlon JR (2010) Americans' Knowledge of Climate Change (New Haven, CT) Available at:

http://environment.yale.edu/climate/files/ClimateChangeKnowledge2010.pdf.

19. Gottfried J, Shearer E (2016) News Use Across Social Media Platforms 2016 Available at: http://assets.pewresearch.org/wpcontent/uploads/sites/13/2016/05/PJ_2016.05.26_social-media-and-news_FINAL1.pdf.

20. Kirilenko AP, Molodtsova T, Stepchenkova SO (2015) People as sensors: Mass media and local temperature influence climate change discussion on Twitter. Glob Environ Chang 30:92-100.

21. IPCC (2014) Climate Change 2014: Synthesis Report. Contribution of Working Groups I, II and III to the Fifth Assessment Report of the Intergovernmental Panel on Climate Change, eds Pachauri RK, Meyer LA (Geneva, Switzerland), p 151.

22. Funk C, Kennedy B (2016) The Politics of Climate.

23. Weber EU (2016) What shapes perceptions of climate change? New research since 2010. Wiley Interdiscip Rev Clim Chang 7(1):125-134.

24. Whitmarsh L (2008) Are flood victims more concerned about climate change than other people? The role of direct experience in risk perception and behavioural response. J Risk Res 11(3):351-374.

25. Weber EU (2010) What shapes perceptions of climate change? Wiley Interdiscip Rev Clim Chang 1(3):332-342.

26. Taylor A, Dessai S, de Bruin WB (2014) Public perception of climate risk and adaptation in the UK: A review of the literature. Clim Risk 4:1-16.

27. Akerlof K, Maibach EW, Fitzgerald D, Cedeno AY, Neuman A (2013) Do people "personally experience" global warming, and if so how, and does it matter? Glob Environ Chang 23(1):81-91.

28. Krosnick JA, Holbrook AL, Lowe L, Visser PS (2006) The Origins and Consequences of democratic citizens' Policy Agendas: A Study of Popular Concern about Global Warming. Clim Change 77(1-2):7-43.

29. Leiserowitz A, Maibach E, Roser-Renouf C, Feinberg G, Howe P (2012) Extreme Weather and Climate Change in the American Mind (Yale Project on Climate Change 
Communication, New Haven, CT).

30. Capstick SB, Pidgeon NF (2014) Public perception of cold weather events as evidence for and against climate change. Clim Change 122(4):695-708.

31. Taylor A, Bruin WB, Dessai S (2014) Climate change beliefs and perceptions of weather-related changes in the United Kingdom. Risk Anal 34(11):1995-2004.

32. Shao W, Goidel K (2016) Seeing is Believing? An Examination of Perceptions of Local Weather Conditions and Climate Change Among Residents in the U.S. Gulf Coast. Risk Anal:1-22.

33. Auer MR, Zhang Y, Lee P (2014) The potential of microblogs for the study of public perceptions of climate change. Wiley Interdiscip Rev Clim Chang 5(3):291-296.

34. Holmberg K, Hellsten I (2015) Gender differences in the climate change communication on Twitter. Internet Res 25(5):811-828.

35. Sisco MR, Bosetti V, Weber EU (2017) When do extreme weather events generate attention to climate change? Clim Change 143(1-2):227-241.

36. Kirilenko AP, Stepchenkova SO (2014) Public microblogging on climate change: One year of Twitter worldwide. Glob Environ Chang 26:171-182.

37. Pearce W, Holmberg K, Hellsten I, Nerlich B (2014) Climate Change on Twitter: Topics, Communities and Conversations about the 2013 IPCC Working Group 1 Report. PLoS One 9(4):e94785.

38. Williams HT, McMurray JR, Kurz T, Lambert FH (2015) Network analysis reveals open forums and echo chambers in social media discussions of climate change. Glob Environ Chang 32:126-138.

39. Jang SM, Hart PS (2015) Polarized frames on "“climate change"' and "'global warming"' across countries and states: Evidence from Twitter big data. Glob Environ Chang 32:11-17.

40. Jacques PJ, Knox CC (2016) Hurricanes and hegemony: A qualitative analysis of micro-level climate change denial discourses. Env Polit 25(5):831-852.

41. Palen L, Starbird K, Vieweg S, Hughes A (2010) Twitter-based information distribution during the 2009 Red River Valley flood threat. Bull Assoc Inf Sci Technol 36(5):13-17.

42. Bruns A, Burgess JE (2012) Local and global responses to disaster: \#eqnz and the Christchurch earthquake. Disaster and Emergency Management Conference (AST Management Pty Ltd.), pp 86-103.

43. Twitter (2011) One hundred million voices. Available at: https://blog.twitter.com/2011/one-hundred-million-voices [Accessed January 6, 2017].

44. Twitter (2012) There are now more than 200M monthly active @twitter users. You are the pulse of the planet. We're grateful for your ongoing support! Twitter. Available at: https://twitter.com/Twitter/status/281051652235087872 [Accessed January 6, 2017].

45. Twitter (2016) Select Company Metrics and Financials Available at: http:/ / files.shareholder.com/downloads/AMDA2F526X/3595129041x0x887900/00A282F9-CADE-410F-92C59A185F407667/Q116_Selected_Company_Metrics_and_Financials.pdf.

46. Liu Y, Kliman-Silver C, Mislove A (2014) The Tweets They Are a-Changin: Evolution of Twitter Users and Behavior. ICWSM, pp 305-314.

47. Greenwood S, Perrin A, Duggan M (2016) Social Media Update 2016 Available at: http://assets.pewresearch.org/wpcontent/uploads/sites/14/2016/11/10132827/PI_2016.11.11_Social-MediaUpdate_FINAL.pdf.

48. Capstick S, Whitmarsh L, Poortinga W, Pidgeon N, Upham P (2015) International trends in public perceptions of climate change over the past quarter century. Wiley 
Interdiscip Rev Clim Chang 6(1):35-61

49. The Weather Channel (2015) The Science Behind Naming Winter Storms at The Weather Channel.

50. Bivand R, Rundel C, Pebesma E, Stuetz R, Hufthammer K (2017) rgeos: Interface to Geometry Engine - Open Source.

51. Pebesma E, et al. (2018) sp: Classes and Methods for Spatial Data.

52. O'Neill S, Williams HT, Kurz T, Wiersma B, Boykoff M (2015) Dominant frames in legacy and social media coverage of the IPCC Fifth Assessment Report. Nat Clim Chang 5(4):380-385.

53. Horton R, et al. (2014) Northeast. Climate Change Impacts in the United States: The Third National Climate Assessment (U.S. Global Change Research Program), pp 371-395.

54. Sharf S (2016) Economics Of A Blizzard: Winter Storm Jonas Is A Win For Whole Foods But A Loss For Hourly Workers. Forbes. Available at: https://www.forbes.com/sites/samanthasharf/2016/01/22/economics-of-ablizzard-winter-storm-jonas-is-a-win-for-whole-foods-but-a-loss-for-hourlyworkers/\#2ab9617f513b [Accessed July 18, 2017].

55. Lubchenco J, Furgione L (2012) Service Assessment: Hurricane Irene, August 21-30, 2011 (Silver Spring).

56. Bruns A, Burgess J (2014) Crisis Communication in Natural Disasters: The Queensland Floods and Christchurch Earthquakes. Twitter and Society, eds Weller K, Bruns A, Burgess J, Mahrt M, Puschmann C (Peter Lang, New York), pp 373-384.

57. Halverson JB, Rabenhorst T (2013) Hurricane Sandy: The Science and Impacts of a Superstorm. Weatherwise 66(2):14-23.

58. Weber EU, Stern PC (2011) Public Understanding of Climate Change in the United States. Am Psychol 66(4):315-328. 